\title{
Evaluations of Smell Threshold Levels and Smell Identification Scores in Turkish Population
}

\author{
Yalçın YILDIRIM, Bayram VEYSELLER, Alper YENIGÜN, Fadlullah AKSOY, Orhan ÖZTURAN
}

Department of Otorhinolaryngology, Bezmialem Vakif University School of Medicine, Istanbul, Turkey

\section{ABSTRACT}

Objective: Evaluation of Turkish smell threshold levels and smell identification scores.

Methods: One hundred and eighty-four healthy subjects, 95 men (51.63\%) and 89 (48.37\%) women were recruited. Smoking history was positive for $57(30.97 \%)$ of the subjects. Head trauma, chronic rhinosinusitis, nasal polyposis, congenital smelling deficiency, psychiatric and neurological disorders such as Parkinson's, Alzheimer's Disease and Multiple Sclerosis were criterias of exclusion. Subjects were given a multiple -choice question for each individual smell and smell identification score was evaluated based on a total of 40 different smells. Smell threshold levels were evaluated with n-butanol test.

Results: Mean butanol threshold level was 6.27 \pm 0.91 (mean \pm SD) (range 3-7). Mean smell identification score was 32.57 $\pm 2.89(\mathrm{mean} \pm$ SD) (range 23-40). Mean smell identification score of women was significantly higher compared to men $(\mathrm{p}<0.001)$. Butanol threshold level scores and smell identification scores were cross-correlated $(\mathrm{p}<0.001)$. Decrease in butanol smell threshold scores were accompanied by decrease in smell identification scores. Smokers scored significantly lower in both butanol threashold and smell identification tests ( $\mathrm{p}<0.001)$.

Conclusion: This emphasizes suggests the importance of olfactory screening test utilization for assessment of olfactory dysfunction in clinical practice. Our smell test is easy to apply, inexpensive and suitable for Turkish population in terms of odour familiarity.

Keywords: Smell, smell test, olfactory functions, smell level, hiposmia, anosmia

\section{Introduction}

Olfactory perception forms the basis of life for some species. Although we are unaware of its significance, olfactory perception has an important place in many stages of our lives. For instance, it helps us in recognizing dangerous situations, such as spoiled food and natural gas leakage, or enjoying the scent of freshly baked bread or a nice perfume.

With respect to the perception of smell, the olfactory nerve is particularly effective, along with the trigeminal, glossopharyngeal, and vagus nerves. For the stimulation of olfactory nerve, olfactory molecule must reach the olfactory region. Determination of a feature of any odor is possible with a combination of many different perceptions. To stimulate the olfactory nerve, olfactory molecules must reach the olfactory region, specifically the olfactory mucosa located in the superior region of the nasal cavity. Although olfactory molecules reach the olfactory mucosa by diffusion, a specific airway flow is required for the perception of odor (orthonasal flow). While eating, olfactory molecules proceed to the olfactory mucosa located in the nasal cavity through the retronasal flow, and they notably contribute to experiencing the flavor of food $(1,2)$.

The most common causes of olfactory dysfunction include upper respiratory tract infections, such as nasal and sinus diseases, and head traumas $(3,4)$. Olfactory dysfunctions have been reported to occur following alcoholism, exposure to toxic chemicals, endocrine diseases (hypothyroidism and diabetes), renal failure, liver failure, neurodegenerative diseases (Alzheimer's disease, Parkinson's disease, and multiple sclerosis), schizophrenia, nasal and intracranial tumors, and surgery (nasal and endoscopic sinus surgery) $(4,5)$. The cause of the loss of smell cannot 
be determined in most patients; this disorder is called idiopathic olfactory dysfunction. Because olfactory dysfunction develops in neurodegenerative diseases, smell testing is currently a part of neurological evaluation.

Although olfaction has a significant role in the life quality of humans, olfactory impairment is paid inadequate attention by physicians. In addition, patients are unaware of their olfactory dysfunctions.

The evaluation of the olfactory function in clinical practice is generally disregarded in Turkey. However, olfactory loss is a finding that supports the diagnoses and guides the explanation of morbidities. In rare situations, in which physicians assess the olfactory function, evaluations are performed with qualitative methods, beyond standardization and quantitative norms.

The tests used for evaluating olfactory perception are subjective, and they do not have a specific standard. During testing, the concentration of the olfactory material, its flow rate, air purity, and application time should be carefully controlled. The patient should be informed regarding the test in detail, and olfactory materials should be presented at certain intervals.

The development of olfactory scanning tests helps physicians in easily and rapidly establishing a diagnosis. This study was conducted to develop an olfactory test battery that is suitable for the Turkish society using odors that are familiar in the Turkish society.

\section{Methods}

The study protocol was approved by the Clinical Studies Ethics Committee; participants were informed regarding the study before written informed consent was received from them.

Between February 1 and March 30, 2011, 184 healthy individuals with ages ranging from 18 to 65 years (mean, $38.72 \pm 11.76$ years) were included in the study. Of the participants, 95 were male $(51.63 \%)$ and 89 were female (48.37\%). Fifty-seven individuals (30.97\%) smoked. Moreover, patients with a head trauma, chronic rhinosinusitis, allergic rhinitis, nasal polyps, psychiatric disorder (psychoses), neurological diseases (Parkinson's disease, Alzheimer's disease, and multiple sclerosis), or congenital olfactory dysfunction were excluded.

During evaluation using the odor discrimination test, participants were asked to mark the choice that they considered to be true for the one among 40 odors that they smelled, and the data obtained were evaluated for calculating odor discrimination scores.

The odor discrimination test includes 40 different odor essences, which were produced in accordance with the

\section{Table 1. Olfactory test materials and answer choices}

\begin{tabular}{|c|c|c|c|c|}
\hline 1 & Vicks & Naphthalene & Grass & Anise \\
\hline 2 & Soap & Naphthalene & Olive oil & Geranium \\
\hline 3 & Honey & Vanilla & Cinnamon & $\begin{array}{c}\text { Chocolate } \\
\text { (Cacao) }\end{array}$ \\
\hline 4 & Tobacco & Milk & Turkish coffee & Chocolate \\
\hline 5 & Cinnamon & Milk & Honey & Vanilla \\
\hline 6 & Lemon & Grapefruit & Peach & Cherry \\
\hline 7 & Hazelnut & Coconut & Soap & Mastic \\
\hline 8 & Henna & Butter & Anise & Olive oil \\
\hline 9 & Ginger & Mustard & Red pepper & Parsley \\
\hline 10 & Pineapple & Grape & Strawberry & Raspberry \\
\hline 11 & Milk & Banana & Coconut & Vanilla \\
\hline 12 & Mandarin & Apple & Strawberry & Grape \\
\hline 13 & Cherry & Lemon & Orange & Strawberry \\
\hline 14 & Rose & Lavender & Pear & Watermelon \\
\hline 15 & Garlic & Onion & Chicken bouillon & Beef bouillon \\
\hline 16 & Cumin & Celery & Mustard & Garlic \\
\hline 17 & Grape & Apple (green) & Cherry & Apricot \\
\hline 18 & Cherry & Raspberry & Strawberry & Peach \\
\hline 19 & Naphthalene & Centaury & Olive oil & Incense/Smoke \\
\hline 20 & Anise & Naphthalene & Lavender & Bergamot \\
\hline 21 & Lavender & Daisy & Jasmine & Rose \\
\hline 22 & Hazelnut & Coconut & Walnut & Peanut \\
\hline 23 & Parsley & $\begin{array}{l}\text { Chicken } \\
\text { bouillon }\end{array}$ & Onion & Incense/smoke \\
\hline 24 & Strawberry & Pineapple & Grape & Peach \\
\hline 25 & Pinewood & Cabbage & Cucumber & Sage \\
\hline 26 & Daphne & Anise & Clove & Melissa \\
\hline 27 & $\begin{array}{l}\text { Stinging } \\
\text { nettle }\end{array}$ & Basil & Anise & Cumin \\
\hline 28 & Honey & Cinnamon & Banana & Vanilla \\
\hline 29 & Tobacco & Coconut & Turkish coffee & Hazelnut \\
\hline 30 & Geranium & Olive oil & Thyme & Linden \\
\hline 31 & Bergamot & Geranium & Basil & Purple basil \\
\hline 32 & Cumin & Onion & Black pepper & Peppermint \\
\hline 33 & Hazelnut & Peanut & Turkish bagel & Tobacco \\
\hline 34 & Strawberry & Raspberry & Cherry & Orange \\
\hline 35 & Bread & Olive oil & Butter & Fish \\
\hline 36 & Daisy & Purple basil & Melissa & Jasmine \\
\hline 37 & Apricot & Pear & Watermelon & Melon \\
\hline 38 & Pineapple & Grape & Strawberry & Apple \\
\hline 39 & Banana & Honey & Milk & Vanilla \\
\hline 40 & Lemon & Mandarin & Grapefruit & Cherry \\
\hline
\end{tabular}




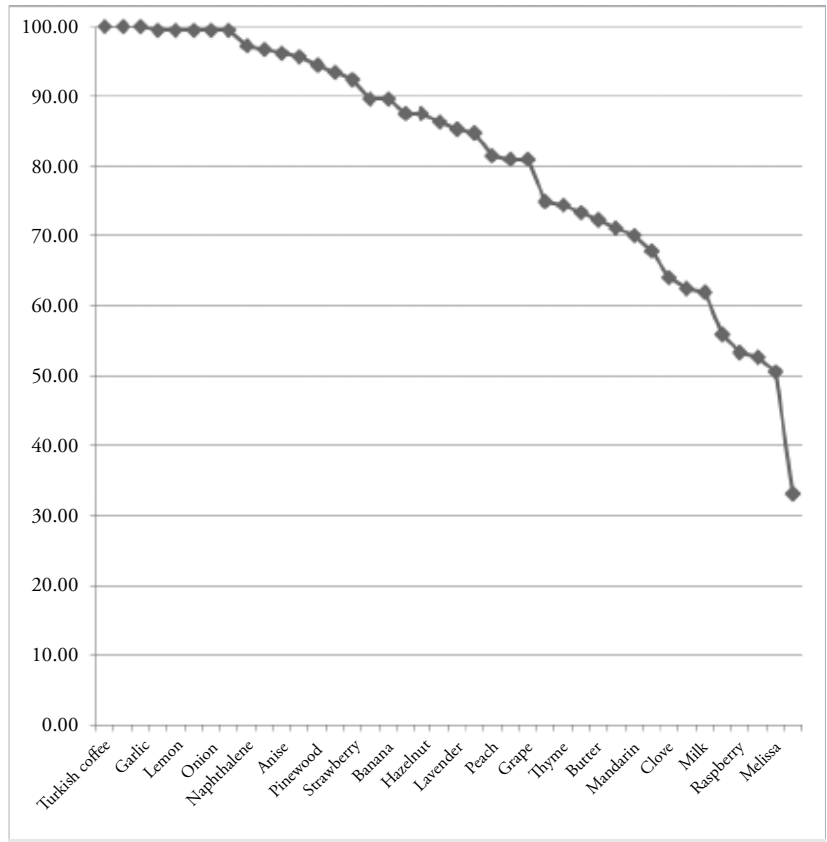

Figure 1. Graph of the percentages of odor recognition

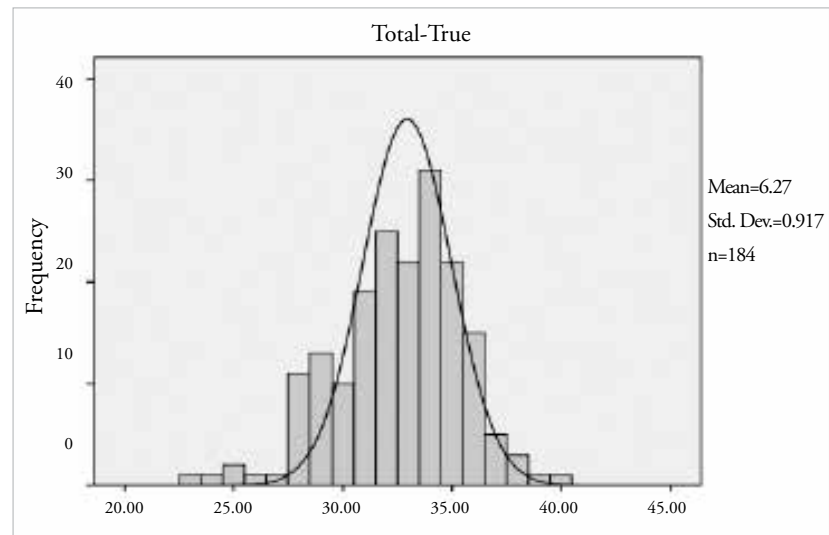

Figure 3. The histogram for the scores of total odor discrimination scores and the number of participants

Turkish Standard Institute and ISO 9001 standards; they were diluted with fluid or propylene glycol and maintained in odor-tight bottles. The tests were performed in a noiseless and well-ventilated room. Each bottle was brought toward the nostrils and was smelled from both nostrils for 3-4 s. Then, the patient was asked to mark the correct choice among the four different odor names and pictures. The bottles were marked only with numbers to prevent patients from being led to a choice. To avoid odor adaptation, $30 \mathrm{~s}$ were allowed to pass between smelling test bottles. Every 10 odors, the test was stopped for $5 \mathrm{~min}$. The orthonasal test battery and answer choices are presented in Table 1.

The butanol threshold test is based on the determination of the lowest concentration that can be perceived. Therefore, butanol is commonly used. Phenylethyl alcohol, which smells like rose, can also be a good alternative to

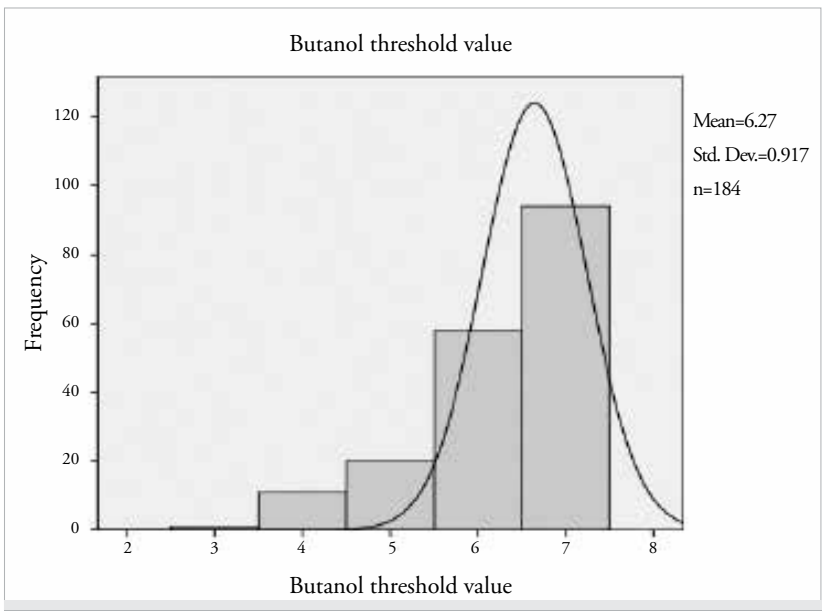

Figure 2. The histogram for the scores of butanol threshold values and the number of participants

butanol because it has a lower trigeminal reactivity. The common reason for selecting these agents is that they can be readily dissolved in water and can be easily recognized. The odors are presented to the patient beginning from the lowest concentration and increasing to the highest. It is important not to begin with highest concentrations because this can lead to sensitivity loss and adaptation. Moreover, the highest concentration can stimulate the common chemical senses and can be perceived even by anosmic individuals. During the test, the patient is presented with two bottles, one of which contains an odor and the other of which is empty, and is asked to identify the bottle with the odor. When the patient distinguishes the bottle with the odor, the question is re-asked and the threshold value is determined whether the patient correctly answers. The most concentrated solution was diluted at the rate of $4 \%$ with distilled water. Other bottles were prepared at 10 different concentrations by diluting with distilled water at the ratio of 3:1. Furthermore, pure distilled water was placed in a similar bottle. Each bottle was tested by asking which of the two bottles contained the odor. One bottle contained butanol, and the other contained pure distilled water. The bottles were brought within $2 \mathrm{~cm}$ of the nostrils of the patient and smelled for 3-4 s. Then, the patient was asked to determine which bottle contained the odor. This procedure was repeated at least three times. When the patient identified the right bottle three times, the related concentration was identified as the threshold value.

\section{Statistical analysis}

The data obtained were analyzed using SPSS (Statistical Package for the Social Sciences Inc.; Chicago, IL, USA) version 16.0 statistical software. For comparing the dependent groups, the Mann-Whitney $U$ test was used. For the independent groups, the sample t-test was employed. A p value of $<0.05$ was accepted to be statistically significant. 
Table 2. Recognition numbers and percentages of odors

\section{Odor}

Turkish coffee

Rose

Garlic

Vicks

Lemon

Incense/Smoke

Onion

Peppermint

Naphthalene

Soap

Anise

Tobacco

Pinewood

Chocolate

Strawberry

Coconut

Banana

Cumin

Hazelnut

Lavender

Honey

Peach

Olive oil

Grape

Chicken bouillon

Thyme

Apple

Butter

Mandarin

Apricot

Clove

Cherry

Milk

Pineapple

Raspberry

Orange

Melissa

Basil

\section{Success percentage}

100.00

100.00

100.00

100.00

99.46

99.46

99.46

99.46

97.28

96.74

96.20

95.65

94.57

93.48

92.39

89.67

89.67

87.50

87.50

85.33

84.78

81.52

80.98

80.98

75.00

74.46

73.37

72.28

70.11

67.93

64.13

62.50

61.96

55.98

53.26

52.72

50.54

33.15

\section{Results}

The butanol threshold values were found to be at least 3 and at most 7 among the participants (mean, $6.27 \pm 0.917)$. The odor discrimination test scores ranged from 23 to 40 (mean, 32.57 \pm 2.89 ) (Figure 1-3).

In the olfactory test scores, the odor of Vicks, for which olfactory perception occurs via the trigeminal nerve, was

Table 3. Distribution and means of age, butanol scores, and recognition numbers of odors according to sex

\begin{tabular}{|c|c|c|c|c|c|c|}
\hline & $\begin{array}{c}\text { Sex } \\
1 \mathrm{~m} 2 f\end{array}$ & $\mathbf{N}$ & Mean & $\begin{array}{c}\text { Std. } \\
\text { Deviation }\end{array}$ & & P \\
\hline \multirow[t]{2}{*}{ Age } & 1.00 & 95 & 38.37 & 10.84 & $t=-0.41$ & 0.679 \\
\hline & 2.00 & 89 & 39.09 & 12.72 & & \\
\hline \multirow{2}{*}{$\begin{array}{l}\text { Butanol } \\
\text { score }\end{array}$} & 1.00 & 95 & 6.13 & 0.99 & $z=-1.93$ & 0.053 \\
\hline & 2.00 & 89 & 6.42 & 0.81 & & \\
\hline \multirow[t]{2}{*}{ Total true } & 1.00 & 95 & 31.71 & 2.87 & $z=-4.11$ & $<0.001$ \\
\hline & 2.00 & 89 & 33.48 & 2.63 & & \\
\hline
\end{tabular}

Table 4. Cross correlation between the ages, butanol threshold values, total odor discrimination scores, and butanol scores of patients and odor discrimination scores

\begin{tabular}{|c|c|c|c|c|c|}
\hline Age & 184 & 18 & 65 & 38.72 & 11.761 \\
\hline Butanol score & 184 & 3 & 7 & 6.27 & 0.917 \\
\hline \multirow[t]{2}{*}{ Total true } & 184 & 23.00 & 40.00 & 32.57 & 2.89 \\
\hline & & Age & $\begin{array}{l}\text { Butanol } \\
\text { score }\end{array}$ & Total true & \\
\hline \multirow{3}{*}{$\begin{array}{l}\text { Median } \\
\text { Correlations }\end{array}$} & & 36.00 & 7.00 & 33.0000 & \\
\hline & & & & & \\
\hline & & Age & $\begin{array}{l}\text { Butanol } \\
\text { score }\end{array}$ & & \\
\hline \multirow[t]{3}{*}{ Butanol score } & r & $-0.483 * *$ & & & \\
\hline & $p$ & $<0.001$ & & & \\
\hline & $\mathrm{N}$ & 184 & & & \\
\hline \multirow[t]{3}{*}{ Total true } & $r$ & -0.136 & $0.384^{* *}$ & & \\
\hline & $p$ & 0.065 & $<0.001$ & & \\
\hline & $\mathrm{N}$ & 184 & 184 & & \\
\hline
\end{tabular}

used as a positive control. All 184 subjects correctly perceived the odor of Vicks. Moreover, the odors of rose, Turkish coffee, and garlic were correctly identified by all participants. Lemon, incense/smoke, onion, and peppermint were correctly distinguished by 183 participants (99.46\%). 179 participants (97.28\%) recognized the odor of naphthalene. The distributions of odors according to their recognition rates and frequencies are shown in Tables 1 and 2 . It was observed that the first 20 odors were correctly distinguished by more than $86.41 \%$ of individuals. The odors that were least known were pineapple, raspberry, orange, Melissa, and basil.

There was a direct correlation between smoking and butanol threshold values and odor discrimination scores. In patients who smoked, both the butanol threshold 


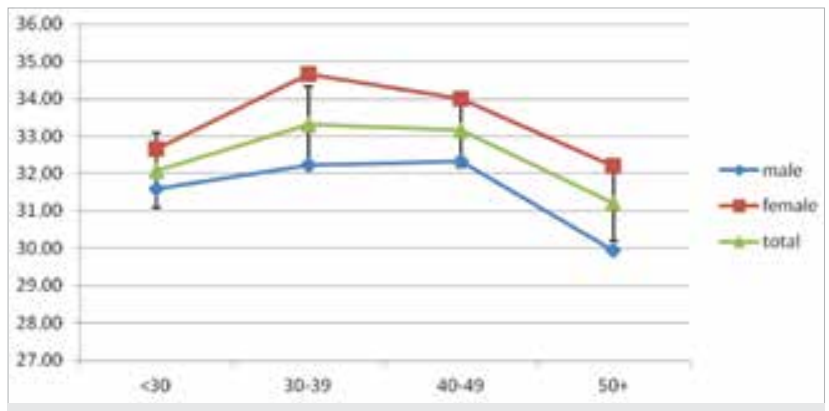

Figure 4. The mean of odor discrimination scores in females, males, and all participants according to decades

values and odor discrimination scores were found to be significantly lower $(\mathrm{p}<0.001$ for both).

The distribution was similar for females and males. No statistically significant difference was found between them $(\mathrm{p}=0.69)$. The mean score of odor discrimination was higher in females than in males, and the difference between them was highly statistically significant $(\mathrm{p}<0.001)$. In the butanol threshold test, the scores were found to be lower in males than in female patients, and the difference was almost significant $(\mathrm{p}=0.53)$ (Table 3-5).

A statistically significant cross-correlation was detected for butanol threshold values and odor discrimination scores $(\mathrm{p}<0.001)$ (Table 3$)$. In parallel with decreased butanol threshold values, an apparent decrease was also observed in odor discrimination scores (Figure 4).

\section{Discussion}

Olfactory perception has an important role in the quality of life of humans. However, olfactory impairments are often inadequately evaluated by physicians, and they are not given due importance.

For evaluating olfactory impairments, there are many psychophysical tests that measure quantitative olfactory function. Thus, numerous olfactory tests have been developed. First, Zwaardemaker (7) developed the tube olfactometer and then many other olfactometers in which saturated air is released and odor is smelled from a bottle; perfumery strips, plastic squeezable bottles, microencapsulated scratchable strips, pens with different odors, and sophisticated olfactometers with air dilution have been developed (7-10).

The development of olfactory scanning tests has helped physicians in rapidly and easily evaluating olfactory functions. When an olfactory impairment is detected, a detailed medical history must be taken and an olfactory scanning test must be used for assessing the presence of normosmia or hypoanosmia. To distinguish conductive or sensorineural olfactory impairments, other examinations must also be performed. Rhinomanometry, nasal cytology, endoscopy, MR, and CT must be applied for evaluating the nose and paranasal sinuses and other olfactory tracts. If neurodegenerative diseases (Alzheimer's disease, Parkinson's disease, and multiple sclerosis) are suspected, a complete neurological examination must be performed in association with olfaction loss.

Olfactory tests are implemented in many health centers worldwide. These are sometimes previously defined tests and sometimes locally designed tests. In Japan, the T\&T olfactometer, which includes sticks with eight different concentrations of five odors, is the standard test. By means of this test, both perception and discrimination thresholds can be determined and they can be drawn on a graph, such as an audiogram (11). In Germany, an odor identification-based forced-choice test, in which felt-tip pens with odors are used, was developed (Sniffin' Sticks, Erlanger) (12).

University of Pennsylvania Smell Identification Test (UPSIT), Cross Cultural Smell Identification Test, Scandinavian Odor-Identification Test, and Sniffin' Sticks Test (SST) are the olfactory test materials that are commercially available and commonly used (13-16).

University of Pennsylvania Smell Identification Test is a microencapsulated test of the olfactory function, which is common in North America (13). This test comprises four booklets with 40 microencapsulated crystals and 10 different odors in each booklet (a total of 40 odors). It is a multiple choice test, and the patient has to choose one of the four choices even if she/he does not smell any odor. UPSIT has been adapted and utilized in many countries, such as Brazil, China, Australia, and Italy (1720). Familiarity with the odors is very important for olfactory testing. The individuals for whom the olfaction evaluation will be performed must be familiar with the odors that will be presented (20).

Sniffin' Sticks Test was developed in Germany considering the European population. It has been available since 1996, and it is commonly used in Europe (10). The odors in the test were chosen among ones with which the Central European population was highly familiar. SST comprises a two-level test. In the first level, odor identification is evaluated using 12 sticks. The second level is the extended SST, and it evaluates odor thresholds, discrimination, and identification $(10,21)$.

In the elderly, the surface of the olfactory epithelium is reduced, the olfactory epithelium changes place with the respiratory epithelium, and the number of mitral cells in the olfactory bulb is decreased (22). Olfactory loss with unknown etiology in advanced age is called presbyosmia. In our study, a decrease was detected in odor discrimination scores and butanol threshold test scores with advanced age. A cross-correlation was observed between the decreases in both the tests (Table 4). 


\begin{tabular}{|c|c|c|c|c|c|c|}
\hline & Cigarette & $\mathbf{n}$ & Mean & Std. Deviatior & & \\
\hline \multirow[t]{2}{*}{ Age } & None & 127 & 38.25 & 11.80 & $t=-0.8$ & 0.424 \\
\hline & Yes & 57 & 39.75 & 11.71 & & \\
\hline \multirow[t]{2}{*}{ Butanol score } & None & 127 & 6.44 & 0.79 & $z=-3.64$ & $<0.001$ \\
\hline & Yes & 57 & 5.88 & 1.05 & & \\
\hline \multirow[t]{2}{*}{ Total true } & None & 127 & 33.22 & 2.61 & $z=-4.35$ & $<0.001$ \\
\hline & Yes & 57 & 31.11 & 2.97 & & \\
\hline Age group & Sex $1 \mathrm{~m} 2 \mathrm{f}$ & $\mathbf{N}$ & Mean & Median & Std. Deviation & \\
\hline \multirow[t]{3}{*}{$1.00<30$} & 1.00 & 27 & 31.5926 & 32.0000 & 2.76321 & \\
\hline & 2.00 & 23 & 32.6522 & 32.0000 & 2.24841 & \\
\hline & Total & 50 & 32.0800 & 32.0000 & 2.57016 & \\
\hline \multirow[t]{3}{*}{$2.0030-39$} & 1.00 & 35 & 32.2286 & 32.0000 & 2.80845 & \\
\hline & 2.00 & 29 & 34.6552 & 34.0000 & 2.00492 & \\
\hline & Total & 64 & 33.3281 & 34.0000 & 2.74327 & \\
\hline \multirow[t]{3}{*}{$3.0040-49$} & 1.00 & 18 & 32.3333 & 33.0000 & 2.24918 & \\
\hline & 2.00 & 18 & 34.0000 & 34.5000 & 2.47339 & \\
\hline & Total & 36 & 33.1667 & 34.0000 & 2.47848 & \\
\hline \multirow[t]{3}{*}{$4.0050+$} & 1.00 & 15 & 29.9333 & 29.0000 & 3.34806 & \\
\hline & 2.00 & 19 & 32.2105 & 32.0000 & 3.24172 & \\
\hline & Total & 34 & 31.2059 & 31.0000 & 3.43581 & \\
\hline \multirow[t]{3}{*}{ Total } & 1.00 & 95 & 31.7053 & 32.0000 & 2.86903 & \\
\hline & 2.00 & 89 & 33.4831 & 34.0000 & 2.62900 & \\
\hline & Total & 184 & 32.5652 & 33.0000 & 2.88885 & \\
\hline
\end{tabular}

Quantitative olfactory assessment is often neglected in clinical practice. However, olfactory loss can support diagnosis and can guide in the explanation of morbidity. All these tests are expensive, and they have not been adapted to the Turkish society. While the mean UPSIT score was found to be 21.00 in a study conducted in Turkey, it was 36 for Americans in the same age group $(23,24)$. This 15-score significant difference between the tests was because of the Turkish participants being unfamiliar with the odor materials in UPSIT as well as because of cultural differences (24).

In addition, in another study performed in Turkey, while the odors that were familiar to the Turkish society were correctly recognized at an approximate rate of $94 \%$, the rate was reduced to $10 \%$ for some odors. This suggests that the odors included in UPSIT are unfamiliar to the Turkish society. In UPSIT test, the odors unfamiliar to the Turkish society, such as partridgeberry, lime, cheddar cheese, alcohol-free beer, and whiskey, decrease the general score (24).

Similarly, in an UPSIT study conducted in Italy, it was reported that the mean score of Italian participants was
6 points lower than that of American participants and 2 points lower than that of Australian participants $(19,20)$.

The UPSIT test is insufficient for evaluating olfactory function in the Turkish population. The mean score of correct answers, which is $21 / 40$, is evaluated to be "severe microsmic" according to American normative values. However, in accordance with the diagnostic criteria prepared according to the normative values for the American population, individuals who can distinguish between 35 and 40 odors are accepted to be normosmic. The use of UPSIT in the evaluation of olfactory function in clinical practice results in false positivity in Turkey. It has been reported that the application of UPSIT according to these criteria is inappropriate because it can result in the diagnosis of false olfactory dysfunction in normosmic individuals $(23,24)$.

Odors are generally recognized based on people's experiences, and people develop their own codes in accordance with cultural teachings. Once odor compounds are encountered, it is difficult to erase them from the memory, even if the event where the compound was encountered has been forgotten (25). 
This study was performed in order to develop a test for the Turkish society because the odors in the tests produced in other countries are unfamiliar to the Turkish people, and their costs are high.

It is suggested that the percentile curves that will be determined after applying the materials of this study in a larger population will be useful in the evaluation of patients with olfactory dysfunctions.

\section{Conclusion}

As a result of this study, olfactory scanning tests are recommended to be used in the routine clinical assessment of olfactory dysfunctions. With the evaluation of 40 different odors, our research is a leading study in the development of an easy, inexpensive, and clear test including odors familiar to the Turkish society.

Ethics Committee Approval: Ethics committee approval was obtained.

Informed Consent: Written informed consent was obtained from patient/patients who participated in this study.

Peer-review: Externally peer-reviewed.

Author Contributions: Concept - B.V.; Design - Y.Y.; Supervision O.Ö.; Funding - F.A.; Materials - Y.Y.; Data Collection and/or Processing - Y.Y.; Analysis and/or Interpretation - B.V.; Literature Review - A.Y.; Writer - B.V.; Critical Review - O.Ö.

Conflict of Interest: The authors declared no conflict of interest.

Financial Disclosure: The authors declared that this study has received no financial support

\section{References}

1. Chilfala WM, Polzella DJ. Smell and taste classification of the smell stimuli. J Gen Pscholl 1995; 122: 287-94. [CrossRef]

2. Sakai N, Kobayakawa T, Gotow N, Saito S, Imada S. Enhancement of sweetness ratings of aspartame by a vanilla odor presented either by orthonasal or retronasal routes. Percept Mot Skills 2001; 92: 1002-8. [CrossRef]

3. Kern RC. Chronic sinusitis and anosmia: pathologic changes in the olfactory mucosa Laryngoscope 2000; 110: 1071-7. [CrossRef]

4. Callahan CD, Hinkebein JH. Assessment of anosmia after traumatic brain injury: performance characteristics of the University of Pennsylvania Smell Identification Test. J Head Trauma Rehabil 2002; 17: 251-6. [CrossRef]

5. Hawkes C. Olfaction in neurodegenerative disorder. Mov Disord 2003; 18: 364-72. [CrossRef]

6. Klimek L, Moll B, Amedee RG, Mann WJ. Olfactory function after microscopic endonasal surgery in patients with nasal polyps. Am J Rhinol 1997; 11: 251-5. [CrossRef]
7. Elsberg CA, Levy I. The sense of smell: I. a new and simple method of quantitative olfactometry. Bull Neurol Inst N Y 1935; 4: 4-19.

8. Cain WS, Gent JF, Goodspeed RB, Leonard G. Evaluation of olfactory dysfunction in the Connecticut Chemosensory Clinical Research Center. Laryngoscope 1988; 98: 83-8. [CrossRef]

9. Doty RL, Shaman P, Dann MS. Development of the university of Pennsylvania smell identification test: a standardized microencapsulated test of olfactory function. Physiol Behav 1984; 32: 489-502. [CrossRef]

10. Kobal G, Hummel T, Sekinger B, Barz S, Roscher S, Wolf S. 'Sniffin' Sticks": screening of olfactory performance. Rhinology 1996; 34: 222-6.

11. Takagi SF. A standardized olfactometer in Japan. A review over ten years. Ann N Y Acad Sci 1987; 510: 113-8. [CrossRef]

12. Wolfensberger M, Schnieper I, Welge-Lusen A. Sniffin'Sticks: a new olfactory test batery. Acta Otolaryngol 2000; 10: 303-6. [CrossRef]

13. Doty RL, Shaman P, Kimmelman CP, Dann MS. University of Pennsylvania Smell Identification Test: a rapid quantitative olfactory function test for the clinic. Laryngoscope 1984; 94: 176-8. [CrossRef]

14. Kobayashi M, Reiter ER, DiNardo LJ, Costanzo RM. A new clinical olfactory function test: cross-cultural influence. Arch Otolaryngol Head Neck Surg 2007; 133: 331-6. [CrossRef]

15. Nordin S, Brämerson A, Lidén E, Bende M. The Scandinavian OdorIdentification Test: development, reliability, validity and normative data. Acta Otolaryngol 1998; 118: 226-34. [CrossRef]

16. Hummel T, Sekinger B, Wolf SR, Pauli E, Kobal G. "Sniffin' Sticks": olfactory performance assessed by the combined testing of odor identification, odor discrimination and olfactory threshold. Chem Senses 1997; 22: 39-52. [CrossRef]

17. Silveira-Moriyama L, Azevedo AM, Ranvaud R, Barbosa ER, Doty RL, Lees AJ. Applying a new version of the Brazilian-Portuguese UPSIT smell test in Brazil. Arq Neuropsiquiatr 2010; 68: 700-5. [CrossRef]

18. Jiang RS, Su MC, Liang KL, Shiao JY, Wu SH, Hsin CH. A pilot study of a traditional Chinese version of the University of Pennsylvania Smell Identification Test for application in Taiwan. Am J Rhinol Allergy 2010; 24: 45-50. [CrossRef]

19. Mackay-Sim A, Grant L, Owen C, Chant D, Silburn P. Australian norms for a quantitative olfactory function test. J Clin Neurosci 2004; 11: 874-9. [CrossRef]

20. Parola S, Liberini P. Assessing olfaction in the Italian population: methodology and clinical application. Ital J Neurol Sci 1999; 20: 287-96. [CrossRef]

21. Kobal G, Klimek L, Wolfensberger M, Gudziol H, Temmel A, Owen $\mathrm{CM}$, et al. Multicenter investigation of 1,036 subjects using a standardized method for the assessment of olfactory function combining tests of odor identification, odor discrimination and olfactory thresholds. Eur Arch Otorhinolaryngol 2000; 257: 205-11. [CrossRef]

22. Doty RL, Shaman P, Applebaum SL, Giberson R, Siksorski L, Rosenberg L. Smell identification ability: changes with age. Science 1984; 226: 1441-3. [CrossRef]

23. Hakyemez HA, Veyseller B, Ozer F, Ozben S, Bayraktar GI, Gurbuz D, et al. Relationship of olfactory function with olfactory bulbus volume, disease duration and Unified Parkinson's disease rating scale scores in patients with early stage of idiopathic Parkinson's disease. J Clin Neurosci 2013; 20: 1469-70. [CrossRef]

24. Yücepur C, Ozücer B, Değirmenci N, Yıldırım Y, Veyseller B, Ozturan O. University of Pennsylvania smell identification test: application to Turkish population. Kulak Burun Bogaz Ihtis Derg 2012; 22: 77-80. [CrossRef]

25. Herz RS, Cupchik GC. The emotional distinctiveness of odor-evoked memories. Chern Senses 1995; 20: 517-28. [CrossRef] 